OPEN ACCESS

Mechanistic Details of the Spontaneous Intercalation of Li Metal into Graphite Electrodes

To cite this article: Christin Hogrefe et al 2020 J. Electrochem. Soc. 167140546

View the article online for updates and enhancements. 


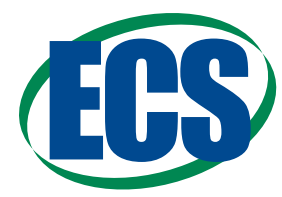

\title{
Mechanistic Details of the Spontaneous Intercalation of Li Metal into Graphite Electrodes
}

\author{
Christin Hogrefe, ${ }^{1, *}$ Simon Hein, ${ }^{2,3}$ (1) Thomas Waldmann,, ,z (i) Timo Danner, ${ }^{2,3}$ \\ Karsten Richter, ${ }^{1, *}$ Arnulf Latz, ${ }^{2,3,4}$ and Margret Wohlfahrt-Mehrens ${ }^{1,3, * *}$ \\ ${ }^{1}$ ZSW-Zentrum für Sonnenenergie- und Wasserstoff-Forschung Baden-Württemberg, D-89081 Ulm, Germany \\ ${ }^{2}$ DLR-German Aerospace Center, Institute of Engineering Thermodynamics, D-70569, Germany \\ ${ }^{3}$ HIU_Helmholtz Institute for Electrochemical Energy Storage, D-89081 Ulm, Germany \\ ${ }^{4}$ UUlm-Ulm University, Institute of Electrochemistry, D-89081 Ulm, Germany
}

\begin{abstract}
The mechanism of the spontaneous intercalation of Li metal into graphite electrodes is highly relevant for aging mechanisms and pre-lithiation of Li-ion cells. In the present work, we introduce a method to investigate this mechanism via measuring the opencircuit-potential $(\mathrm{OCP})$. Experiments without electrolyte, with organic solutions without and with $\mathrm{LiPF}_{6}$ reveal details on the reaction mechanism at $29{ }^{\circ} \mathrm{C}$. The electrodes are investigated by Raman spectroscopy and glow-discharge optical emission spectroscopy (GD-OES) depth profiling to reveal the spatial distribution of the lithiated phases. The analytical information is enriched by simulations with the Battery and Electrochemistry Simulation Tool (BEST). The combination of tools gives interesting insights into the behavior of negative electrodes regarding re-intercalation of deposited $\mathrm{Li}$ into graphite and its kinetics, development of inhomogeneities during aging, as well as pre-lithiation and post-mortem analysis methodology.

(C) 2020 The Author(s). Published on behalf of The Electrochemical Society by IOP Publishing Limited. This is an open access article distributed under the terms of the Creative Commons Attribution 4.0 License (CC BY, http://creativecommons.org/licenses/ by/4.0/), which permits unrestricted reuse of the work in any medium, provided the original work is properly cited. [DOI: 10.1149/ 1945-7111/abc8c3]
\end{abstract}

Manuscript submitted July 15, 2020; revised manuscript received November 2, 2020. Published November 18, 2020.

Supplementary material for this article is available online

Li-ion cells are nowadays used to power most mobile devices such as smart-phones or power tools. For the improvement of electric cars, a long life-time and fast-charging capability with reduced costs and a very high safety level are required for increased consumer acceptance. ${ }^{1}$ Especially the fast-charging capability, lifetime, and safety are connected to the kinetics of Li intercalation into negative electrodes via the aging mechanism of $\mathrm{Li}$ deposition. ${ }^{1-7}$

It is well known from previous studies ${ }^{8-12}$ that electrochemically deposited $\mathrm{Li}$ metal can intercalate spontaneously into graphite electrodes. From thermodynamic point of view, a reaction is spontaneous when the Gibb's free energy

$$
\Delta G=\Delta H-T \Delta S=-z F E
$$

gets negative. Reynier et al. ${ }^{13}$ demonstrated that especially in the early stages of lithiation the further intercalation of $\mathrm{Li}$ in $\mathrm{Li}_{\mathrm{x}} \mathrm{C}_{6}$ is a favored reaction (highest negative $\Delta H$ and most positive $\Delta S$ ). This can also be seen from the positive potential of non-lithiated graphite vs $\mathrm{Li} / \mathrm{Li}^{+}$.

In $\mathrm{Li}$-ion cells, electrochemical re-intercalation of deposited $\mathrm{Li}$ into graphite is evident from features in the negative electrode potential ${ }^{8}$ and in the cell voltage curves, ${ }^{5,7,9-11,14}$ as well as neutron diffraction, ${ }^{9,12,15}$ Post-Mortem analysis, ${ }^{5}$ and accelerated rate calorimetry (ARC). ${ }^{14}$ Zinth et al. ${ }^{12}$ and von Lüders et al. ${ }^{9}$ observed the reintercalation process into graphite electrodes with operando neutron diffraction in commercial 18650-type cells. They showed that the $\mathrm{LiC}_{12}$ phase decreases and the $\mathrm{LiC}_{6}$ phase increases during the relaxation after charging. ${ }^{9,12}$ We observed by neutron diffraction that $\mathrm{Li}$ deposited on a $\mathrm{Si} / \mathrm{C}$ electrode re-intercalates into graphite and is then re-distributed to the Si compound. ${ }^{15}$ Wandt et al. ${ }^{16}$ investigated $\mathrm{Li}$ deposition with operando electron paramagnetic resonance and observed the re-intercalation of $\mathrm{Li}$ as well. However, there is still a lack of knowledge on the mechanistic details. For example, the roles of the electrolyte and conductive salt in this reaction are not well known.

Furthermore, the reaction of $\mathrm{Li}$ metal with negative electrodes is also important to compensate capacity losses during the first cycle by pre-lithiation of negative electrodes. ${ }^{17-23}$ Different groups performed

\footnotetext{
*Electrochemical Society Student Member.

**Electrochemical Society Member.

${ }^{\mathrm{z}}$ E-mail: thomas.waldmann@ $\mathrm{zsw}$-bw.de
}

pre-lithiation by contacting $\mathrm{Li}$ metal pieces or stabilized $\mathrm{Li}$ metal powder (SLMP) with negative electrodes and electrolyte. ${ }^{17-23}$ Shellikeri et al. ${ }^{19}$ investigated pre-lithiation of hard carbon and graphite electrodes with SLMP in comparison to $\mathrm{Li}$ metal stripes in the presence of electrolyte. Holtstiege et al. ${ }^{20}$ observed the reaction of SLMP with graphite directly by nuclear magnetic resonance (NMR) spectroscopy. The authors showed that the decay of the Li amount follows an exponential function. ${ }^{20}$ To the best of our knowledge, the spontaneous reaction of $\mathrm{Li}$ metal with graphite electrodes has not been investigated in spatial resolution, although this is highly relevant for homogeneity in applications such as pre-lithiation as well as reintercalation of deposited Li metal.

In this study, the spontaneous reaction of Li metal in contact with graphite electrodes was investigated by measurement and simulation of the open-circuit potential (OCP). New insights into the reaction mechanism and spatial distribution of lithiated graphite intercalation compounds (GIC) are gained by systematic GD-OES depth profiling and Raman spectroscopy experiments including electrolyte variation and electrode modifications. The interpretation of the measurements is supported by 3D electrochemical simulations which allow additional insight to the "operando" redistribution of Li during reintercalation. The combination of tools provides a comprehensive picture of the spontaneous $\mathrm{Li}$ metal re-intercalation into graphite negative electrodes.

\section{Methods}

Experimental methods.-Commercial graphite electrodes with non-spherical particles, particle sizes of $1-12 \mu \mathrm{m}, 30 \%$ porosity, $2.56 \mathrm{mAh} \mathrm{cm}^{-2}$ areal capacity, double side coated (coating thickness (single side): $56 \mu \mathrm{m}$ ) were dried overnight at $130{ }^{\circ} \mathrm{C}$. A polished $\mathrm{Li}$ metal disk $($ diameter $=16 \mathrm{~mm}, \mathrm{~m}=22.6 \mathrm{mg} \pm 0.9 \mathrm{mg}, \mathrm{d}=256 \pm$ $8 \mu \mathrm{m})$ was pressed with an $8 \mathrm{~kg}$ metal block for $10 \mathrm{~min}$ on the electrode surface and dried for $18 \mathrm{~h}$ at $80{ }^{\circ} \mathrm{C}$ in a vacuum oven. The basic electrolyte solution in all experiments was $900 \mu \mathrm{l}$ EC:EMC (3:7 by weight) +2 wt.-\% VC with different $\mathrm{LiPF}_{6}$ concentrations (0 M, $1 \mathrm{M})$. In all experiments, Celgard 2325 was used as separator. All setups were stored between two aluminum plates using four springs (approx. $0.1 \mathrm{~N} \mathrm{~cm}^{-2}$ ).

In pouch half cells (graphite with $\mathrm{Li}$ pressed on top vs Li metal counter electrode) the OCP was measured for 2 weeks (data point 
recorded every $0.005 \mathrm{~V}$ or $20 \mathrm{~min}$ ). The measurements were conducted using a Maccor 4200 cycler in an Ar-filled glove box $\left(\mathrm{O}_{2}<\right.$ $\left.0.1 \mathrm{ppm} ; \mathrm{H}_{2} \mathrm{O}<0.1 \mathrm{ppm}\right)$ and started before the electrolyte was added.

The respective different electrode geometries for long time storage experiments (no modification, interrupted coating and $\mathrm{Li}$ on $\mathrm{Cu}$ ) are shown in Figs. 1a-1c. The interruption $(1 \mathrm{~mm})$ in Fig. $1 \mathrm{~b}$ was introduced by laser ablation. These electrodes were wrapped in Celgard, sealed into non-transparent pouch foil and filled with $900 \mu \mathrm{l}$ electrolyte. The $\mathrm{LiPF}_{6}$ concentration in the electrolyte was varied $(0 \mathrm{M}, 1 \mathrm{M})$. These set ups were stored at $29{ }^{\circ} \mathrm{C}$ for four weeks. Table I shows an overview of all experimental setups in this study. All experiments were reproduced at least once.

For Raman spectroscopy, the electrodes were washed (DMC, 3 times for $1 \mathrm{~min}$ ) and sealed into a transparent pouch bag inside an $\mathrm{Ar}$ filled glovebox. The spectra were recorded with a Bruker Senterra R200L using a Nd:YAG $(531 \mathrm{~nm})$ laser (Power: $5 \mathrm{~mW}, 20 \mathrm{X}$ objective, Integration time: $55 \mathrm{~s}$, Co-Addition: 10).

GD-OES analysis was carried out using a GDA750 device (Spectruma). A radio frequency method was used, applying $550 \mathrm{~V}$ discharge voltage and a gas pressure of $2 \mathrm{hPa}$. A mixture of 1 vol.- $\%$ $\mathrm{H}_{2}$ in $\mathrm{Ar}$ (both 6.0 purity) was used as analysis gas. For the wavelength detection, the following element specific wavelengths were used: $\mathrm{O}(130.2 \mathrm{~nm}), \mathrm{C}(156.1 \mathrm{~nm})$, and $\mathrm{Li}(670.7 \mathrm{~nm})$ with a max. resolution of $\pm 10 \mathrm{pm}$. All GD-OES samples (area: $4.9 \mathrm{~mm}^{2}$ ) had been prepared in an Ar-filled glovebox and the measurements were conducted without exposure to air.

Model description.-The simulations in this work are performed with the Battery and Electrochemistry Simulation Tool BEST ${ }^{24}$ which is

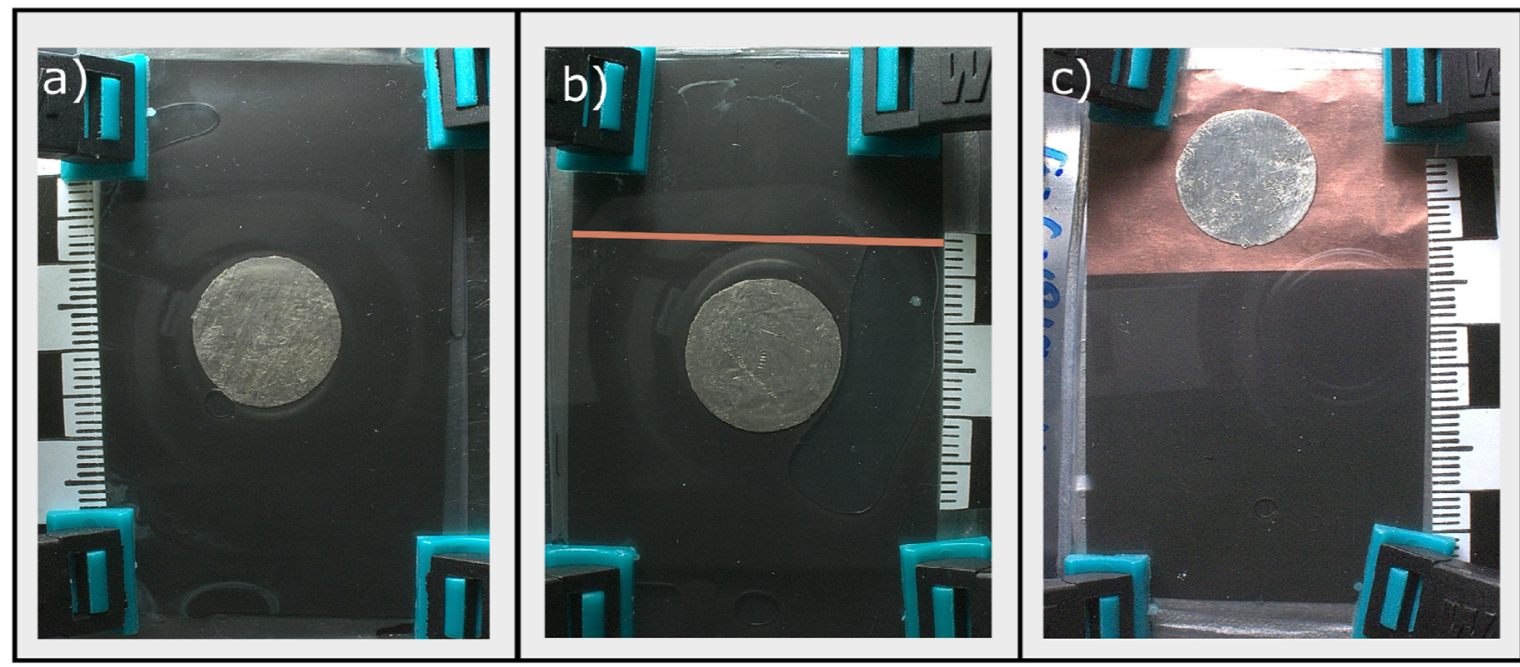

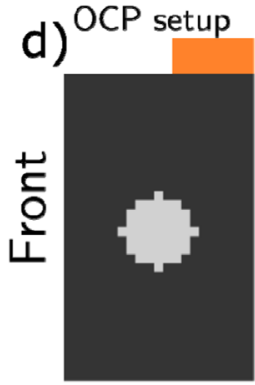
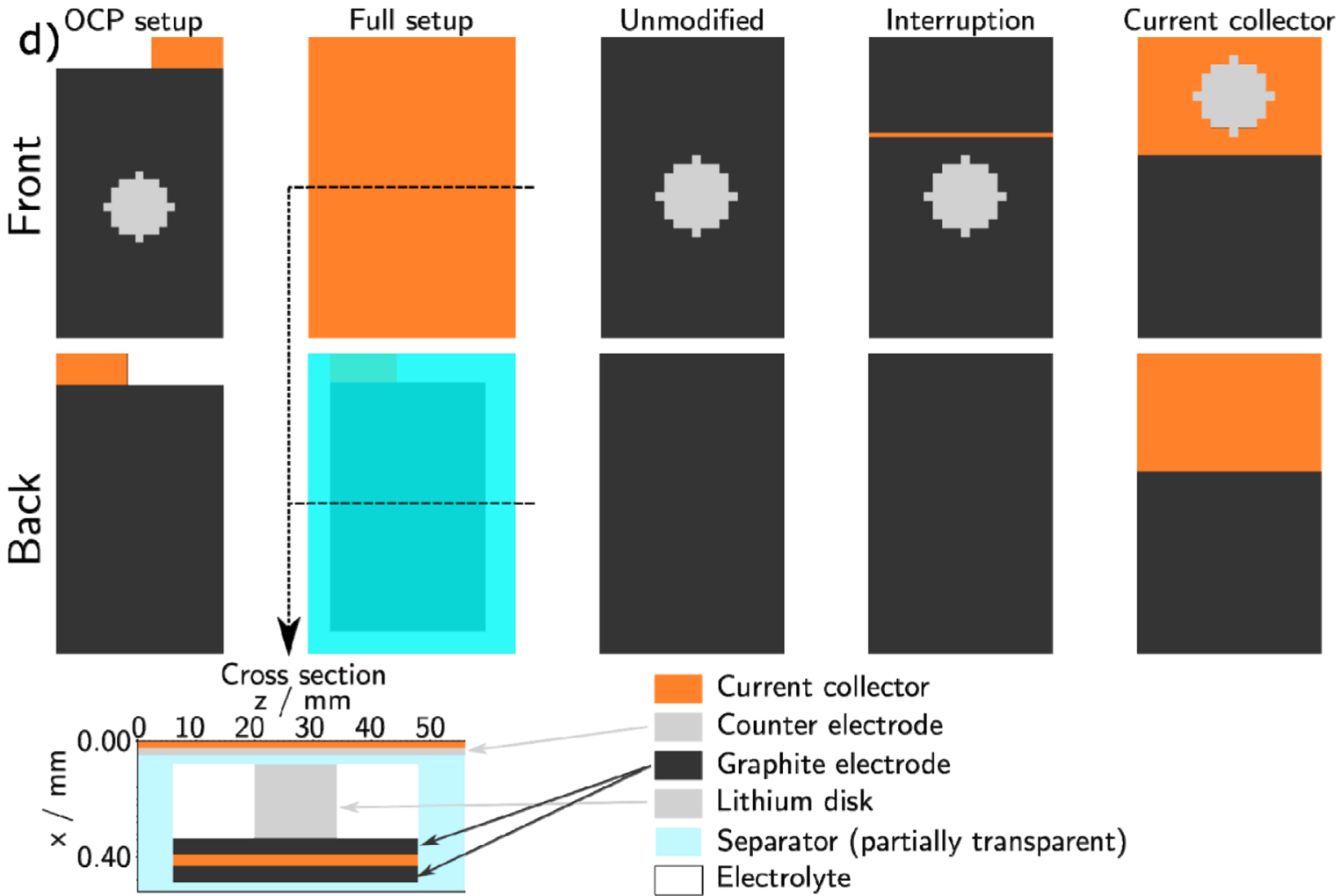

Figure 1. Experimental setups with Li metal disk on graphite electrode (a) unmodified, (b) with $1 \mathrm{~mm}$ interruption of graphite coating (the position of the interruption was enhanced graphically for better visibility), (c) Li metal disk on Cu current collecting foil, not in direct contact with coating. (d) The simulated electrodes for the four different setups from the front and the back and the full simulation domain with a cross section are shown. 
Table I. Overview on experiments.

\begin{tabular}{|c|c|c|c|c|c|c|c|c|}
\hline \# & $\mathrm{T}\left({ }^{\circ} \mathrm{C}\right)$ & $\mathrm{LiPF}_{6}$ in electrolyte & Setup (Figure X) & Li Disk (d in mm) & $\mathrm{OCP}$ & $\begin{array}{l}\text { Raman spectro- } \\
\text { scopy }\end{array}$ & GD-OES depth profiling & Time \\
\hline 1 & $\mathrm{RT}$ & $1 \mathrm{M}$ & a & 16 & $\mathrm{X}$ & & & 2 weeks \\
\hline 2 & 29 & - & a & 16 & & & $\mathrm{X}$ & 4 weeks \\
\hline 4 & 29 & $1 \mathrm{M}$ & a & 16 & & $\mathrm{X}$ & & 4 weeks \\
\hline 5 & 29 & $1 \mathrm{M}$ & $\mathrm{b}$ & 16 & & $\mathrm{X}$ & & 4 weeks \\
\hline 6 & 29 & $1 \mathrm{M}$ & $\mathrm{c}$ & 16 & & $X$ & & 4 weeks \\
\hline
\end{tabular}

developed in a collaboration between Fraunhofer ITWM Kaiserslautern and the DLR Institute of Engineering Thermodynamics. This simulation tool can provide temporal and spatial distribution of $\mathrm{Li}$ concentration, potential and temperature. In this work, a simplified electrochemical model was developed to describe the process of spontaneous lithiation. This model resolves both sides of the graphite electrode, the Li disk, the separator and the counter electrode. A similar model describing $\mathrm{Li}$ stripping within an electrode microstructure was already presented by Hein et $\mathrm{al}^{25}$ and serves as basis for the simulations. The working principle of the model is sketched in the following. A more detailed description of the model can be found in the supporting information section S1 (available online at stacks.iop.org/JES/167/140546/mmedia).

The graphite electrode is modelled as a porous, homogeneous medium. The $\mathrm{Li}$ transport through the materials occurs on three different time scales: Li diffusion from the surface of a particle towards the center ( $\mu \mathrm{m}$ scale: $t=\frac{x^{2}}{D_{S_{o}}} \approx 10^{3} s$ ), Li diffusion between different active material regions of the electrode ( $\mathrm{cm}$ scale: $t=\frac{x^{2}}{D_{S o}^{E f f}} \approx 10^{11} \mathrm{~s}$ ) and Li diffusion within the electrolyte (cm scale: $t=\frac{x^{2}}{D_{E l}} \approx 10^{7} \mathrm{~s}$ ). The diffusion within a Graphite particle is fast compared to the two other processes and the overall experimental duration. Hence, the $\mathrm{Li}$ diffusion into a Graphite particle is neglected and the Li distribution within the Graphite particle is described by the local mean concentration. The Li diffusion inside the homogenized phase between different regions of the electrodes are described by a mass balance equation with an effective diffusion coefficient $D_{S o}^{E f f}=\frac{\epsilon_{\mathrm{So}}}{\tau_{\mathrm{So}}} D_{S o}^{\text {Bulk }}=\epsilon_{S o}^{\beta_{S o}} D_{S o}^{\text {Bulk }}$, with solid volume fraction $\epsilon_{S o}=0.7$, tortuosity $\tau_{S o}=1.19$ or a corresponding Bruggeman factor $\beta_{S o}=1.5$. Electrical currents throughout the Li disk and the graphite electrode are described through a charge conservation equation. The three most prominent reactions included in the model are the Li de-/intercalation at the graphiteelectrolyte-interface, the Li dissolution at the interface between Li disk and electrolyte and the $\mathrm{Li}$ reaction at the counter-electrode. The investigated setups contain interfaces between pure $\mathrm{Li}$ and electrolyte. At these interfaces, the formation of a so called solid electrolyte interphase (SEI) occurs, which is one of the main degradation processes inside Li ion batteries. The modelling of SEI formation is a complex topic itself and focus of several recent publications. ${ }^{26,27}$ The growth of a SEI reduces the dissolution of metallic Li and increases the potential drop across the interface. In the presented paper, the growth of the SEI is neglected due to the additional complexity.

Figure 1d shows schematically the simulation domain. The side of the electrode with the Li disk is defined as "front" and the other side as "back." For the electrochemical simulations, the four different electrodes are each surrounded by a separator. In the case of the simulation of the OCP-setup, a counter electrode is placed on top of the separator on the front side. The full simulation domain for the OCP-setup is shown from the front, the back and as a cross section along a center line. The electrochemical parameters for the electrolyte and the graphite are taken from the literature ${ }^{28-30}$ and a list of all Parameters is given in Table S1.

The simulation tool is applied to four different experimental setups, which all involve the $1 \mathrm{M}$ electrolyte. Namely, setup 4) with the Li disk on the unmodified electrode, setup 1) with the Li disk on the unmodified graphite electrode and a counter electrode for OCP measurements, setup 5) on the interrupted electrode, and setup 6) on the current collector next to the electrode. A summary of the setups is given by the corresponding numbers Table I.

\section{Results and Discussion}

OCP measurements of $\mathrm{Li}$ in contact with graphite.-During the spontaneous reaction between $\mathrm{Li}$ metal and graphite, a mixed potential is developing. This leads to a change in the OCP, which is trackable in half cells. In the following, the OCP is measured between a $\mathrm{Li}$ metal counter electrode and a double side coated graphite anode in contact with a Li metal disk (see Fig. 1d).

The experimental (solid lines) and simulated (dotted line) decay of the OCP is shown in Figures $2 a$ and $2 b$. A steep decrease in the
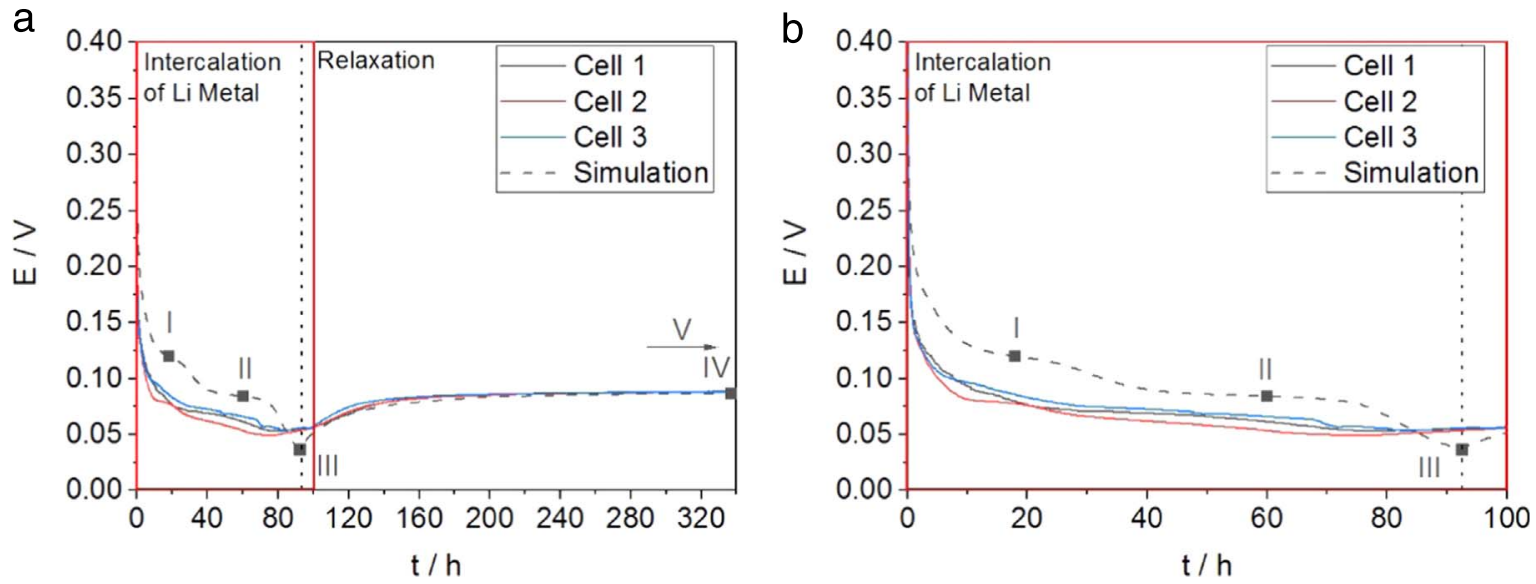

Figure 2. (a) Cell voltage of the three measured cells and the electrochemical simulation. Four of the five points for selected 3D results in Fig. 3 are marked with squares. A voltage minimum is reached between $74 \mathrm{~h}-84 \mathrm{~h}$ (experiment) and $92 \mathrm{~h}$ (simulation). The red square emphasizes the zoomed in part for (b). 
potential can be observed within the first $20 \mathrm{~h}$ in the experiments as well as the simulation. After $74 \mathrm{~h}-84 \mathrm{~h}$ in the experiments and $92 \mathrm{~h}$ in the simulation a minimum in potential is reached (Fig. 2b). The potential is rising up to $88 \mathrm{mV}$ after $14 \mathrm{~d}$, in both, experiment and simulation (Fig. 2a).

The minimum in the curve divides the potential curve in Fig. 2 into two regions. In the first part of the relaxation, $\mathrm{Li}$ metal is still present on the surface of already partially lithiated graphite. Therefore, the OCP exhibits a mixed potential, which is determined by the remaining metallic $\mathrm{Li}$ and the lithiated GIC. Due to the continuous decrease of $\mathrm{Li}$ metal and increase of intercalated $\mathrm{Li}$, the potential is shifted towards lower values.

The minimum of the voltage curve in Fig. 2 indicates the point in time, at which the Li metal is completely dissolved. The dissolution of Li metal was proven experimentally by opening the cells after $336 \mathrm{~h}$ (Fig. 3f) and is consistent with the behavior of deposited $\mathrm{Li}$ during rest after charging. $5,7-12,14,15,31$ The main difference is that deposited Li metal often shows a dendritic micro structure, whereas the Li metal is compact in our experiment.

The second part of the relaxation starts after the minimum of the potential. In this part, $\mathrm{Li}$ is mainly redistributed. Since we observe lithiation of the electrode on both sides (see below), this equilibration proceeds most likely mainly via Li diffusion in the electrolyte. As a result, the OCP slowly increases until a nearly constant voltage $(88 \mathrm{mV})$ is reached after more than $200 \mathrm{~h}$.

We note that the available $\mathrm{Li}$ amount in the experiment was theoretically enough to lithiate the whole electrode up to $60 \%$, which means the OCP should reach the potential of the stage II-I plateau. In literature, this plateau was determined to be in the range of $80-100 \mathrm{mV}$, which is in agreement with our measurements $(88 \mathrm{mV}) .{ }^{11,32}$ However, the post-mortem analysis and simulation results indicate that the graphite electrodes are still not fully equilibrated after $336 \mathrm{~h}$. Therefore, the $\sim 60 \%$ of lithiation represents a mean value and the lithiation degree in the graphite electrode is inhomogeneous.

The numerical simulations allow a semi-quantitative analysis of this experiment. In the first part of the OCP measurements (Fig. 2b) our simulations nicely illustrate that the decrease in cell voltage is indeed due to the intercalation of Li-ions in graphite in the presence of a remaining Li phase. Although the model does only qualitatively capture the dissolution kinetics, it allows us to gain some mechanistic insights on the redistribution of $\mathrm{Li}$ in the cell. Also considering the other setups investigated in this work.

The reasons for the quantitative deviation in the first period can be manifold. In our simulations we chose to use parameters from the literature of a similar graphite system and minor deviations e.g. in the chemical diffusion coefficient and OCV can be expected. Moreover, the tortuosity of transport pathways in the graphite and the pore space will affect transport dynamics. Another factor influencing the dynamics is the formation of surface layers both on the exposed graphite and $\mathrm{Li}$ surfaces which is for the sake of simplicity not considered in this study. These interphases will affect the kinetics of the dissolution and intercalation reactions. More specifically, we expect that such an SEI will reduce the dissolution rate on the time scale of the experiment. In our future work, an additional refinement of our model and parameters will be needed to provide reliable predictions in an actual cell setup. Still, this is not in the focus of this work since we are interested in a qualitative mechanistic understanding of relevant processes in the model setups at hand.

Therefore, it has to be pointed out, that our simulation predicts particularly well the long-term cell potential given by the graphite electrode close to electrochemical equilibrium (see IV in Fig. 2a). This indicates that most of the Li metal is intercalated in the graphite electrode and losses due to parasitic reactions are minor. Our model nicely reproduces the recovery of the cell voltage which shows that the relevant mechanisms for the redistribution of $\mathrm{Li}$ on cell level are on the right time and length scales. Moreover, the simulations provide some interesting insights on the dissolution process of the metallic $\mathrm{Li}$ phase, which are presented in the paragraphs below.

In order to demonstrate the redistribution of Li, Fig. 3 shows the state-of-charge (SOC) distribution of the graphite electrodes at five different points in time (I-V, also marked in Fig. 2). The color scale of the images is extracted from Harris et al.. ${ }^{33}$ The different colors also indicate the different stages during the lithiation of graphite where light grey color corresponds to the pristine state and the golden color to almost full lithiation.

The upper panels in Fig. 3 show the front of the graphite electrode with the Li disk in the center. The graphite beneath the $\mathrm{Li}$ disk always exhibits the highest SOC. In our simulations the Li is completely dissolved after $\mathrm{t}=92 \mathrm{~h}$ while there is still some remains

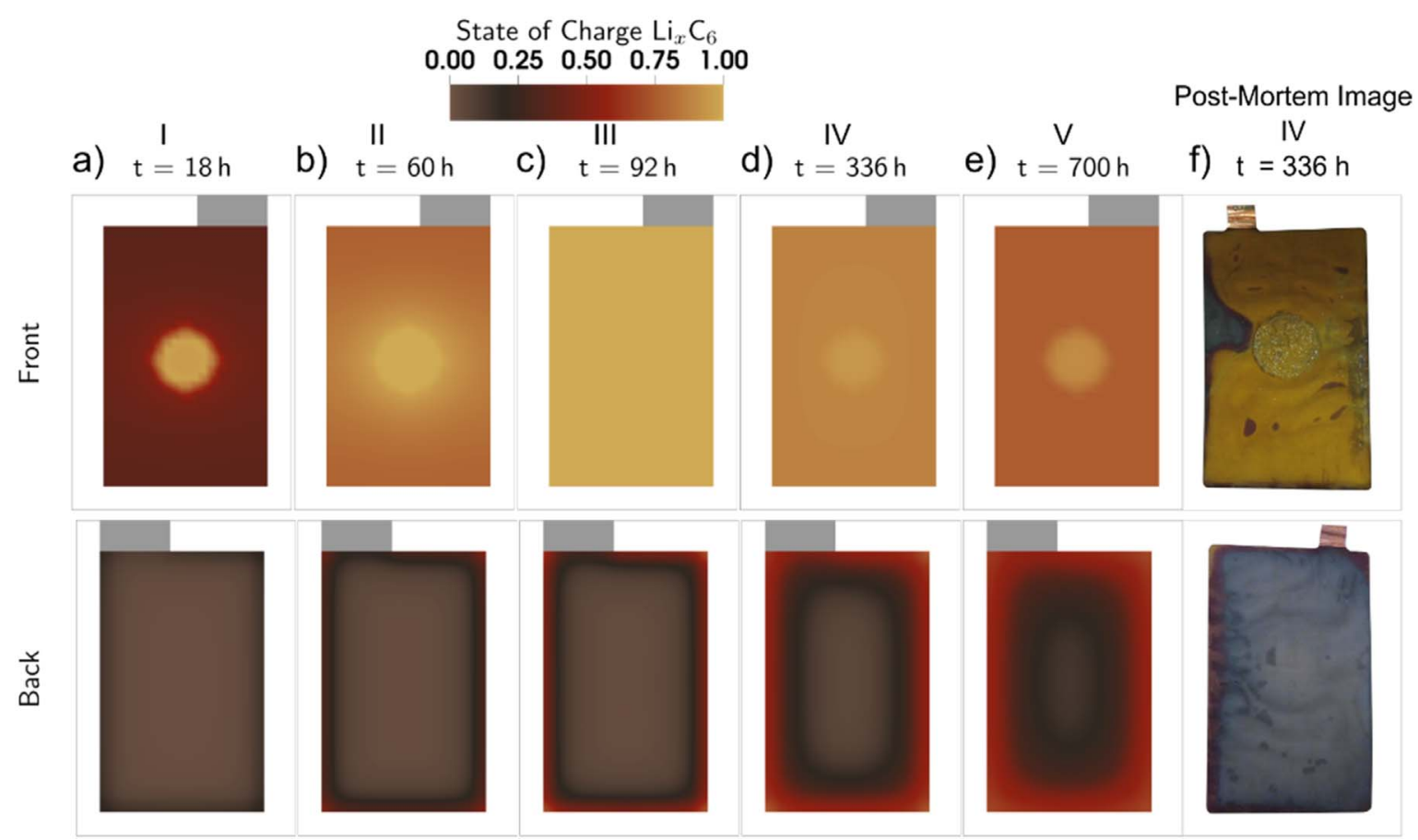

Figure 3. The lithiation state of the front and back graphite electrode from (a)-(e) simulations and (f) experiment. 
Change in thickness of counter-electrode / $\mathrm{mm}$

a)

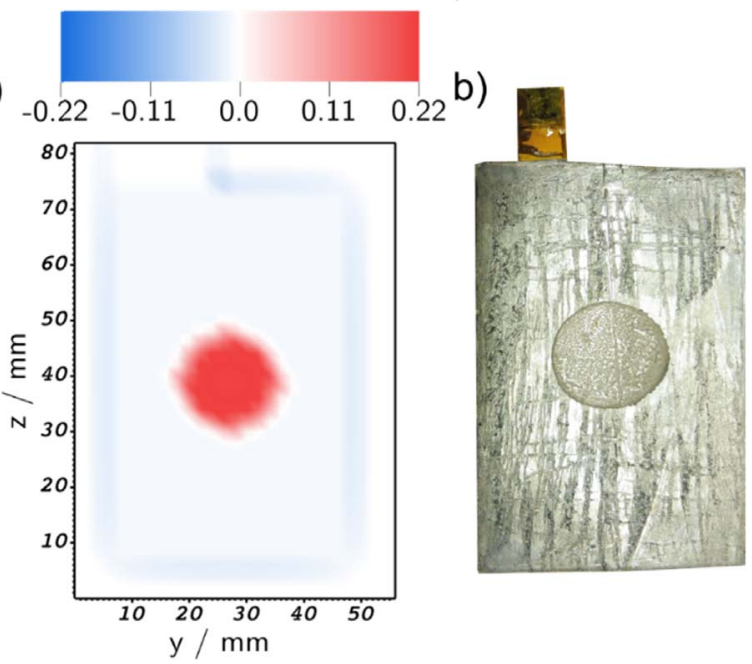

Figure 4. (a) Thickness variation on the surface of the counter-electrode at the end of the simulation. (b) Image of $\mathrm{Li}$ counter electrode after cell opening.

of the Li disk found on the electrode surface in the post-mortem analysis. The bright spot seen in our simulations at $\mathrm{t}>92 \mathrm{~h}$ indicates the former position of the $\mathrm{Li}$ disk after dissolution. $\mathrm{Li}$ is redistributing slowly in this area since we still assume a blocking layer on the electrode surface with the dimensions of the former Li disk. This is consistent with the remaining film of mossy Li observed in the experiments. More details of the simulation setup are described in the Supporting Information S1. Still, we note that the redistribution dynamics as measured by the OCP at $\mathrm{t}>92 \mathrm{~h}$ are very well captured by our simulations. After $18 \mathrm{~h}$, almost complete lithiation of the graphite directly below the disk is observed in the simulations (Fig. 3a, point I). During this first step, the lithiation of graphite is fast which also corresponds to a relatively rapid decrease of the OCP. At point II in Fig. 3b, the SOC is already close to $75 \%$ and the diameter of the lithiated region starts to broaden. Finally, after $92 \mathrm{~h}$ at point III in Fig. 3c, the Li disk is totally dissolved and the surface of the electrode is completely lithiated. In the subsequent point IV in Fig. 3d, the SOC difference between the front and the back of the graphite coating and the resulting difference in electrochemical potential drive the redistribution of the $\mathrm{Li}$ from the front side to the back of the electrode. Even after $700 \mathrm{~h}$, no homogeneous SOC distribution is observed (Fig. 3e). The process of equilibration continues slowly, since the small difference in OCP at the front and the back is nearly fully compensated by the potential drop through the electrolyte.

The lower series of images in Fig. 3 shows the SOC at the back of the graphite electrode. Initially (Fig. 3a, point I), the lithiation is only observed at the edges of the electrode sheet. Moreover, the pattern is slightly inhomogeneous due to the current collector tab in the upper left corner. After longer periods, the SOC at the edges increases and the lithiated regions start to grow towards the center of the electrode. Finally, at the end, the simulations predict an SOC of $50 \%$ close to the edges and $25 \%$ in the center.

We would like to highlight that the simulated distributions are in excellent qualitative agreement with the color patterns observed in the post-mortem analysis in Fig. 3f (corresponding to IV). The front graphite coating in the experiment is (besides some spots) fully lithiated, just as in the simulation. We note that since vacuum sealing was not possible in the current experimental setup, there was probably still additional $\mathrm{Ar}$ in the cell and soaking of the electrolyte was apparently not sufficient at the lower lithiated spot on the left hand side Fig. 3f.

At the back of the electrode (Fig. 3f), most parts of the edges show the characteristic red color, which is typical for $\mathrm{LiC}_{12}{ }^{34}$ and corresponds to $50 \%-75 \%$ SOC as suggested by the simulation (Fig. 3d).
The simulations show that the presence of the metallic Li phase causes a redistribution of the $\mathrm{Li}$ within each electrode. Consequently, we do observe internal currents, both electric and ionic in nature, which changes the local electrochemical environment within the cell. In this respect, it is interesting to notice that the internal currents in the electrolyte also affect the Li distribution at the $\mathrm{Li}$ metal counter-electrode. Our simulations predict locally slightly higher currents in the center of the electrode opposite to the Li metal disk. This is a sign of a redistribution of the $\mathrm{Li}$ metal at the counter electrode. Indeed, we found a small protrusion directly opposite to the $\mathrm{Li}$ disk in the post-mortem analysis. The electrochemical simulations allow to define the change in thickness of the counter electrode with respect to its initial thickness. The local variations are presented in Fig. 4. The large extrusion in the center of the counter electrode, which is directly opposite to the location of the Li disk, exhibits an absolute height of about $0.33 \mathrm{~mm}$ relative to the surrounding surface. The maximum deviation from the initial electrode plane ranges from -0.11 to $0.22 \mathrm{~mm}$ in the simulation. This is in reasonable agreement with the experiments, where the thickness of the deposit is between 0.34 and $0.40 \mathrm{~mm}$ and showed a different morphology than the other parts of the counter electrode. $\mathrm{Li}$ is known to deposit in dendritic and mossy structures, ${ }^{35-40}$ which are less dense than the metallic $\mathrm{Li}$ on the counter electrode.

We would like to note that the reaction is different in experiments with $\mathrm{Li}$ in contact with graphite electrode without a counter electrode. It is striking that the Li metal disk is not completely dissolved after 4 weeks compared to the $3 \mathrm{~d}$ during the OCP measurements in the half cells (see above). The main differences between those two experimental series are the presence of a $\mathrm{Li}$ counter electrode and the external connection between the counter electrode and the graphite electrode. A disturbance due to a leaking current through the external connection, as reported e.g. in case of supercapacitors $^{41}$ has to be excluded. This possibility could be ruled out because of the high internal resistance of the Maccor channel $(>10 \mathrm{M} \Omega)$ as well as and by experiments without external electrical connection and $\mathrm{Li}$ counter electrode. This indicates that the $\mathrm{Li}$ counter electrode might disturb the system in a way, which allows for a faster dissolution of the Li disk.

As discussed above, internal current and Li-ion flows at the counter electrode were present in the simulation. These internal currents result in closed current loops, which do not depend on an external connection. The counter electrode, which spans the complete graphite electrode, enables a current distribution with a smaller resistance than the electrolyte. Hence, Li can dissolve at the Li disk, migrate to the counter electrode and deposited at the surface. To maintain charge neutrality, Li-ions are dissolved further away from the center of the counter electrode. This leads most likely to a faster dissolution of the Li disk and a more homogeneous current distribution throughout the electrolyte between the counter electrode and the graphite electrode. Thus, enhancing the $\mathrm{Li}$ intercalation probability all over the electrode. ${ }^{42}$ In the experiments without a counter electrode, these current do not exist. Hence, the Li disk will dissolve at a much slower pace. Additional simulations, which do not include a large counter electrode, support this explanation and can be found in the supporting information (see section S2 in the supporting information). The influence of the location and size of the counter electrode on the $\mathrm{Li}$ dissolution is an interesting topic, however, it is beyond the scope of this work. A short investigation on the impact of a smaller counter electrode on the $\mathrm{Li}$ dissolution and $\mathrm{Li}$ distribution within the cell is added to the supporting information.

Li transport pathways.-Figure 5 gives an overview on possible processes (1-5) in the reaction of Li metal with a graphite negative electrode:

1) Dissolution of $\mathrm{Li}$ metal, diffusion of $\mathrm{Li}$-ions in electrolyte, intercalation into graphite particles.

2) Transfer of $\mathrm{Li}$ from $\mathrm{Li}$ metal to graphite particles in direct contact (solid state reaction). 


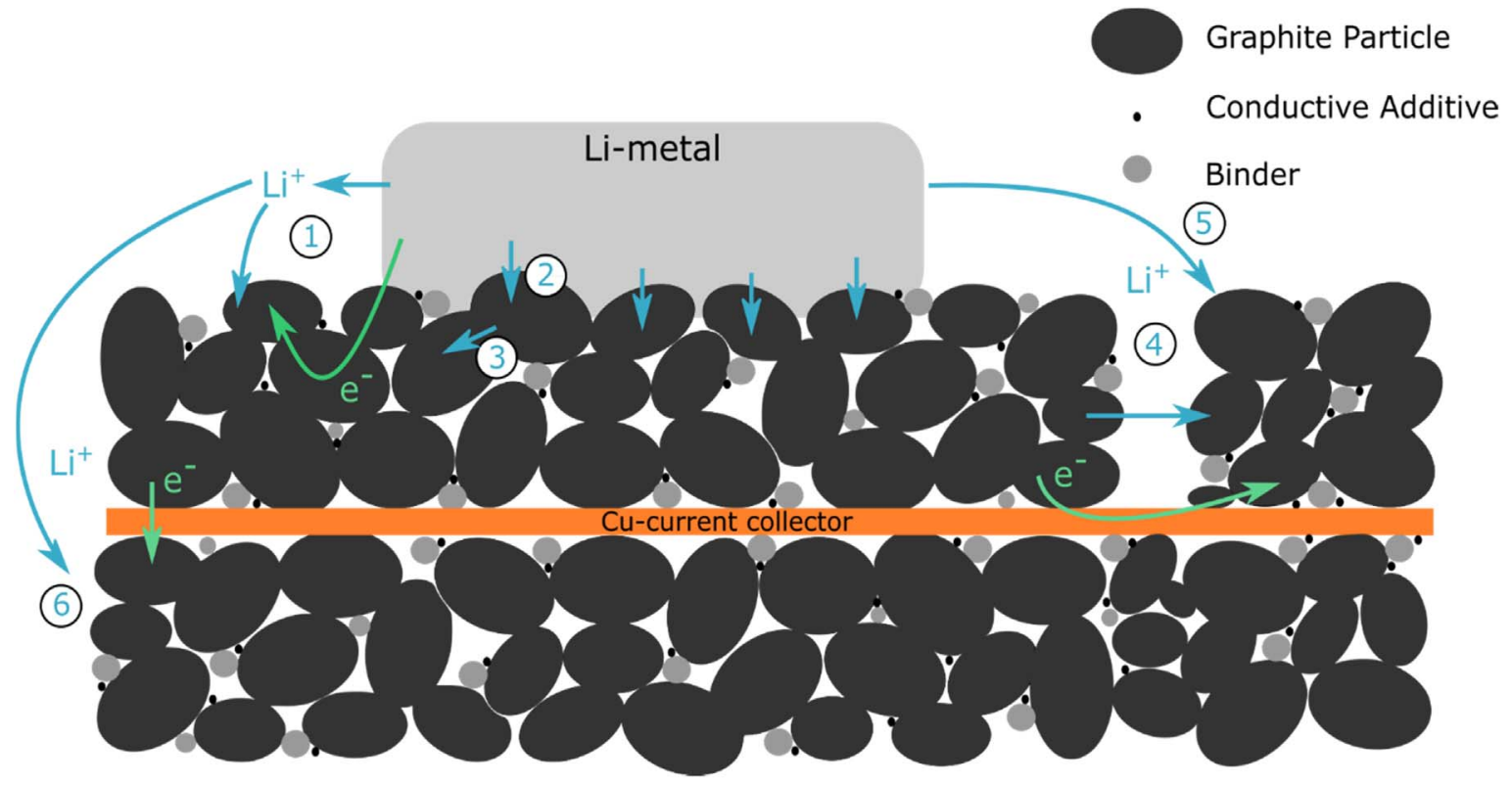

Figure 5. Possible Li transport pathways in the reaction of $\mathrm{Li}$ metal with a graphite electrode.

3) Transfer of Li from graphite to other graphite particles in direct contact (solid state reaction).

4) De-intercalation from graphite, diffusion of Li-ions in electrolyte, intercalation into to other graphite particles.

5) Dissolution of $\mathrm{Li}$ metal, diffusion of $\mathrm{Li}$-ions in electrolyte, intercalation into a graphite particle behind a gap in the electrode coating.

6) Dissolution of $\mathrm{Li}$ metal, diffusion of Li-ions in electrolyte, intercalation into a graphite particle on the back of the electrode.

In literature, most authors considered the Li-ion diffusion processes $1,{ }^{19,20}$ and $4,{ }^{43}$ as most relevant although 5 and 6 might also be possible. In order to investigate the Li transport pathways of Li metal pressed onto a graphite electrode systematically, the following experiments were carried out. In particular, Li metal disks are pressed onto the surface of a graphite electrode with defined pressure and temperature. As discussed above, these experiments were conducted without a counter electrode.

The different configurations are shown in Figs. 1a-1c and all setup conditions (electrolyte and geometries) are summarized in Table I and discussed in the following sections. In Fig. 6, all electrodes are shown after storage for 4 weeks at $29^{\circ} \mathrm{C}$. Li metal is still present in all cases and colored lithiated GIC can be observed.

Li transport pathway without electrolyte.-When no electrolyte is present (Fig. 6a and Fig. 7a), only a few spots underneath the $\mathrm{Li}$ metal disk show a golden color, indicating the $\mathrm{LiC}_{6}$ phase. ${ }^{11,34,44}$ In this experiment, no other colored GIC phases were observed. These optical observations were confirmed with Raman spectroscopy and GD-OES (Figs. 7b-7d). The measurements were conducted at the golden and grey colored regions of the electrode (squares in Fig. 7a). Because of overlapping signals from the transparent pouch foil and graphite signals, only the $\mathrm{G}-$ band $\left(\mathrm{E}_{2 \mathrm{~g}} \text { mode, } 1581 \mathrm{~cm}^{-1}\right)^{45,46}$ could be analyzed. Raman spectra in the golden colored area (A in Fig. 7a) showed nearly no Raman intensity in the region of the graphite G-band vibration, which is in accordance with the observation during in situ Raman spectroscopy experiments of fully lithiated graphite from by Inaba et al.. ${ }^{45}$ The grey regions (B in Fig. 7a) showed a typical graphite Raman spectrum.

In contrast to the Raman spectra, which represent the electrode surface, GD-OES allows to measure depth profiles. Li was only detected in the golden area A with GD-OES, which is shown in Fig. 7c. The depth profile showed that there is still some metallic $\mathrm{Li}$ attached at the surface, because the measured $\mathrm{Li}$ amount is above the expected value for $\mathrm{LiC}_{6}(\sim 8 \mathrm{wt} .-\% \mathrm{Li}$, emphasized by a dashed line in Fig. 7c). Only the first few $\mu \mathrm{m}$ of the electrode surface are fully lithiated and the Li content is decreasing exponentially within the electrode. No Li was detected with GD-OES depth profiling in the grey area $\mathrm{B}$ as can be seen from Fig. $7 \mathrm{~d}$.

Already in the $1980 \mathrm{~s}$, different surface science groups reported that adsorbed $\mathrm{Li}$ atoms spontaneously intercalate into graphite single crystals. ${ }^{47,48}$ The energy barrier for that reaction was reported to be $0.16 \pm 0.02 \mathrm{eV}$ under ultra-high vacuum conditions. ${ }^{44}$ The analysis of this setup proved the possibility of solid state diffusion (pathway 2 and 3) without electrolyte at ambient temperature and moderate pressure. Most likely, the Li metal, which is pressed into the upper pores, leads to lithiation of the graphite particles to the top of the electrode.

The observed situation is similar in dried out parts of aged Li-ion cells with Li deposition. I.e. re-intercalation of previously deposited Li metal can most likely take part also in such parts of the electrode, although it is slower compared to areas with electrolyte.

Li transport pathway with carbonate electrolyte (without conductive salt).- - If no conductive salt is present in the carbonate solution, the complete area underneath the Li metal disk is golden (Fig. 6b and Fig. 7e). Around the golden area, a dark grey circle is observable, indicating a slightly lithiated GIC. ${ }^{11}$ With Raman spectroscopy (Fig. 7f) and GD-OES (Figs. $7 \mathrm{~g}$ and $7 \mathrm{~h}$ ) the $\mathrm{LiC}_{6}$ phase at the surface of the graphite electrode was proven, however, no Li was detected in the dark parts of the electrode (Fig. 7h). The higher areal lithiation of graphite indicates that the solvent molecules might be participating in the process, if no conductive salt is present. The used liquid consists of EC, EMC, and VC. We speculate that EC might be involved in the mechanism. ${ }^{49-52}$ Another possibility would be an "electron-ion-electrolyte" complex, which was proposed by Yazami et al. ${ }^{53}$ However, from the present data, it cannot be concluded which counter ions are involved.

Li transport pathway with carbonate electrolyte (with conductive salt).- - In a typical electrolyte solution with conductive salt, all colored lithiated GIC phases (gold: $\mathrm{LiC}_{6}$, red: $\mathrm{LiC}_{12}$, blue: $\mathrm{LiC}_{18}{ }^{33,34}$ ) are observable (Fig. $6 \mathrm{c}$ ). Compared to the experiments without electrolyte and with only carbonate solution (see above), the Li metal disk is clearly more dissolved. With Raman spectroscopy (Fig. 8b), the presence of lithiated GIC phases at the measured areas 


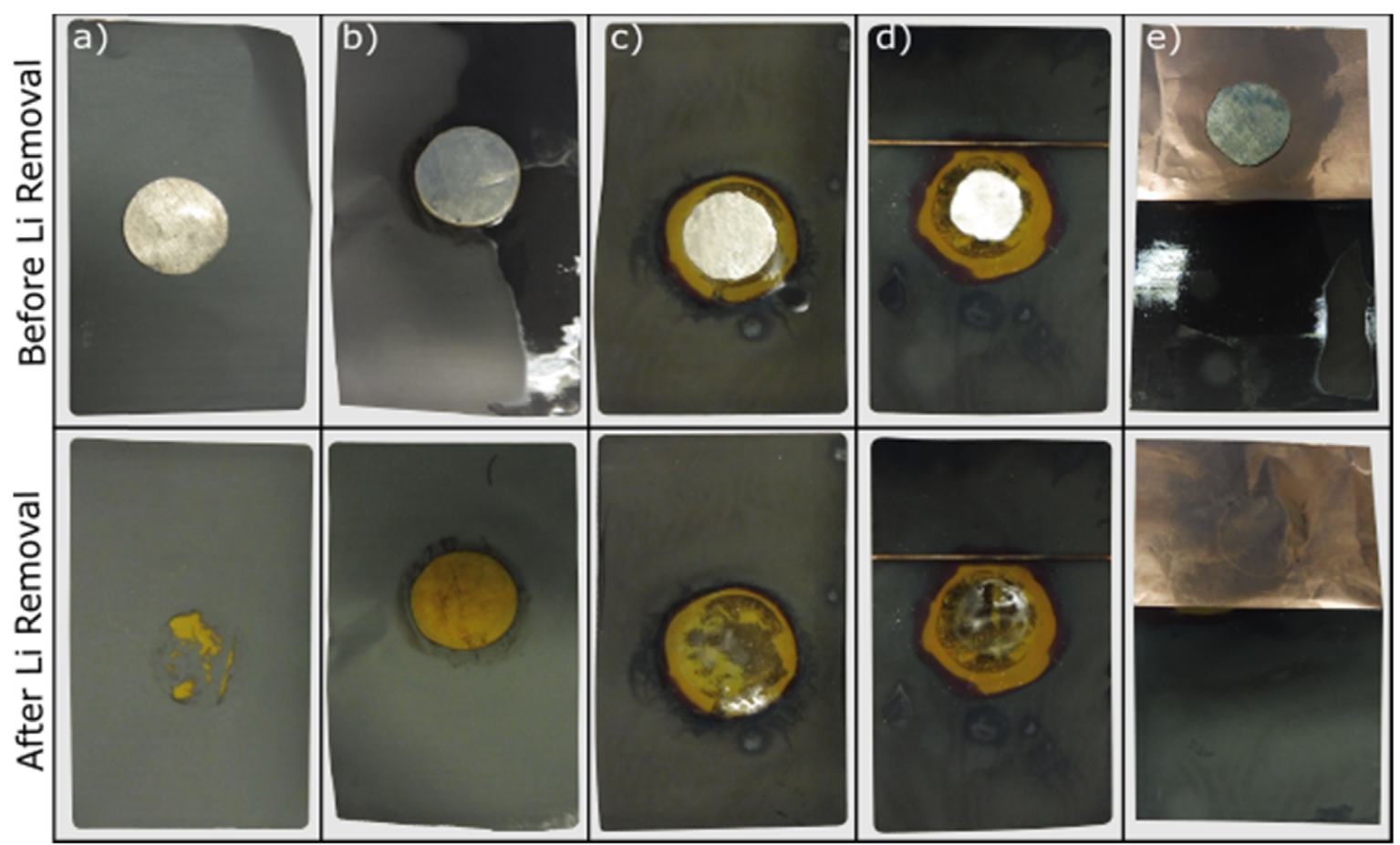

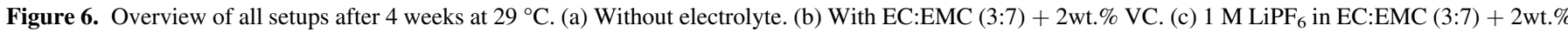
VC. (d) Interrupted electrode $(1 \mathrm{~mm})$ in $1 \mathrm{M} \mathrm{LiPF}_{6}$ in EC:EMC $(3: 7)+2 \mathrm{wt} . \%$ VC. (e) Li pressed on copper in $1 \mathrm{M} \mathrm{LiPF}_{6}$ in EC:EMC (3:7) + $2 \mathrm{wt} . \%$ VC.

(A-G Fig. 8a) was proven. According to Inaba et al. ${ }^{45}$ and Hardwick et al., ${ }^{54}$ the changes of the $\mathrm{G}-\mathrm{Band}\left(\mathrm{E}_{2 \mathrm{~g}}\right.$ mode) are observable through shifts to higher wavelength (A, D-G in Fig. 8b) and appearance of doubled structure (B and $\mathrm{C}$ in Fig. 8b) for stage IV and III GICs. ${ }^{45,46,54}$ With increasing distance to the former Li metal center, the concentration of $\mathrm{Li}$ inside graphite seems to decrease. The back of the electrode (E-G in Fig. 8b) shows according to the Raman spectra a similar lithiation state as the outer parts of the front (A and D in Fig. 8b). The electrochemical simulation (Fig. 8c) shows on the front a high lithiation directly beneath the Li disk and a decrease of lithiation with increasing distance. On the back, the center region shows a constant lithiation with a lower state of charge than the outer parts. However, differences are minor and, therefore, presumably hard to detect in the corresponding measurements. Driving force for the distribution of charge are potential differences between different lithiated GIC phases, ${ }^{4,55}$ which could explain the relatively fast initial lithiation of graphite and the slow lithiation for higher lithiated GIC phases.

The observed situation is similar as in Li-ion cells with deposited $\mathrm{Li}$ on the graphite electrode in the presence of electrolyte with conductive salt. The results are similar to literature. ${ }^{17,19,20,22}$ In these publications, only the chemical lithiation reaction velocity was investigated. Our experiments show additionally the spatial distribution pathways of $\mathrm{Li}$ within the electrode. The fact that the reaction is faster in the presence of electrolyte, suggests that pre-lithiation should also be performed in this way.

Li transport beyond interruptions of the electrode coating.When the graphite electrodes in $1 \mathrm{M} \mathrm{LiPF}_{6}$ electrolyte solution were interrupted (Figs. 6d and 8d), the colored lithiated GIC phases were observed also behind the interruption. Raman spectroscopy proved (A in Fig. 8e) that the lithated GIC were the same with the same distance from the former $\mathrm{Li}$ metal center regardless the interruption (B in Fig. 8e). The back was homogeneously lithated (C-E in Fig. 8e). The simulation (Fig. 8f) shows similar results. The lithiation of the graphite particles behind the gap can only be lithiated by Li-ion diffusion (pathway 5 in Fig. 5) through the electrolyte, indicating this to be the dominant $\mathrm{Li}$ transport pathway.
With Li only in electrical contact with the electrode coating (Li pressed on $\mathrm{Cu}$; Figs. 6e and 8g), after 4 weeks only the upper edge shows the red and golden lithiated GICs phases (A in Fig. 8g). This is also the case in the simulation, where the largest lithiation can be found at the upper edge beneath the Li disk (Fig. 8i). The dissolution of $\mathrm{Li}$ in the experiment and the simulation was also mainly at the lower edge. In the Raman spectra (Fig. 8h), it is shown, that both back and front of the electrode are lithiated. In the front, a $\mathrm{Li}$ gradient decreasing from the former $\mathrm{Li}$ metal disk center is observed (A-C in Fig. 8h). This gradient is not so distinct at the back (D-F in Fig. 8h). As can also be seen in the simulation result (Fig. 8i). In this setup, diffusion of Li-ions is not necessarily needed, i.e. $\mathrm{e}^{-}$could react with $\mathrm{Li}$-ions, which are mostly homogeneously distributed in the electrolyte (also at the back of the electrode).

\section{Conclusions}

We present a systematic study on the Li transport pathways in the spontaneous reaction of $\mathrm{Li}$ metal with a graphite electrode. Li metal disks were pressed on the graphite electrode in graphite/Li vs $\mathrm{Li}$ pouch half cells. The changes in potential showed a minimum where the Li metal is dissolved completely. The experiments agree with the simulations regarding the voltage relaxation, charge distribution, and changes of the Li counter electrode.

Experiments with intentionally blocked pathways yield interesting insights into the reaction mechanism. We showed that the chemical lithiation of graphite without electrolyte is possible, however, at $29{ }^{\circ} \mathrm{C}$ this is the slowest transport pathway. In organic solutions without conductive salt the lithiation process seems to be enhanced compared to the case without electrolyte, however, the kinetics are still much slower than in the experiments where electrolyte with $\mathrm{LiPF}_{6}$ is present.

The main Li transport pathway is the lithiation of graphite via $\mathrm{Li}$ ion diffusion through the electrolyte. Interrupted parts of the electrode coating and even the back of double-side coated electrodes take part in the relaxation process. Raman experiments confirmed the presence of GIC phases at all parts of the electrode as soon as electrolyte is present. The diffusion of $\mathrm{Li}$-ions supports the main and fastest Li transport pathways (electrochemical pathways 1 and 4-6 in 

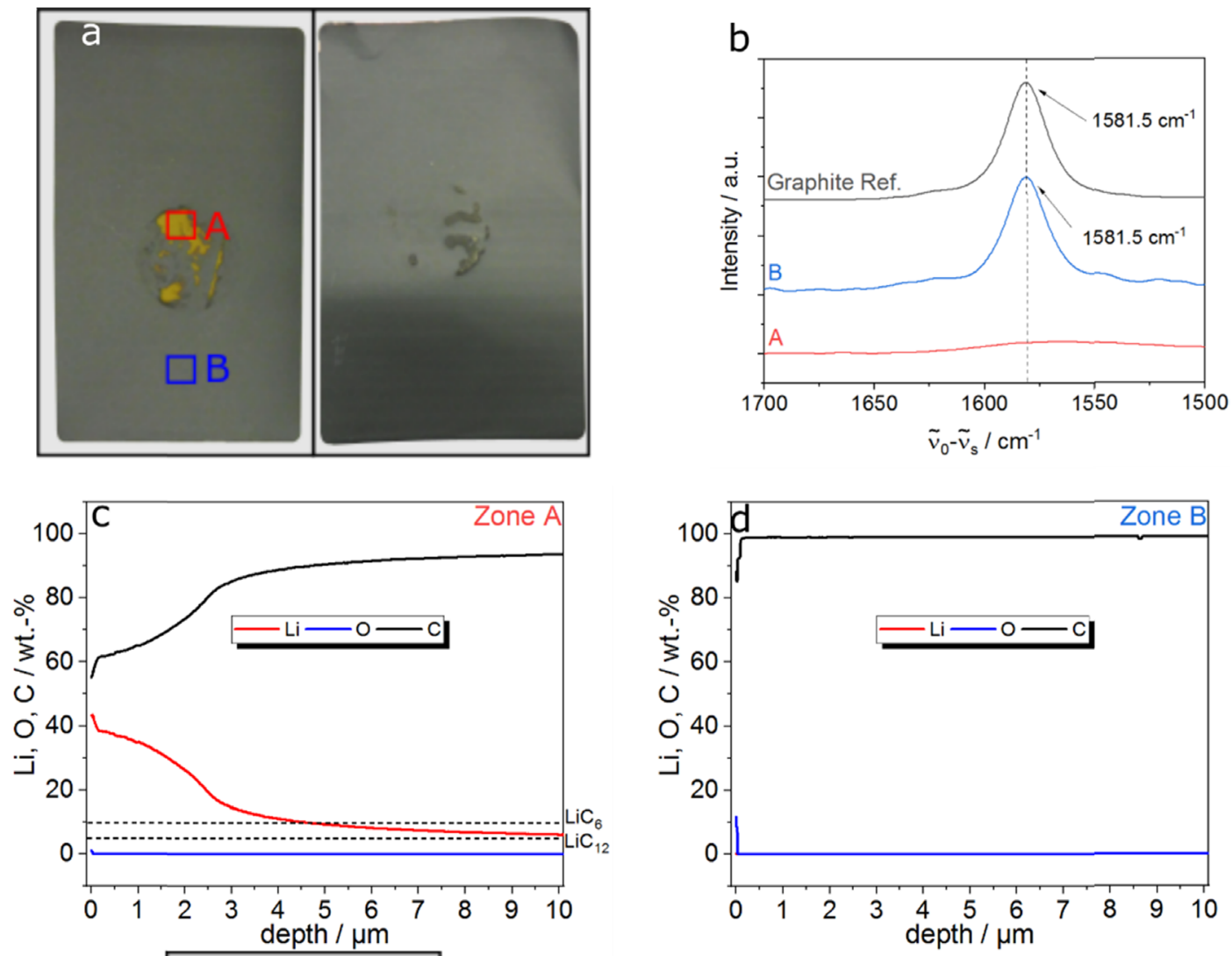

e
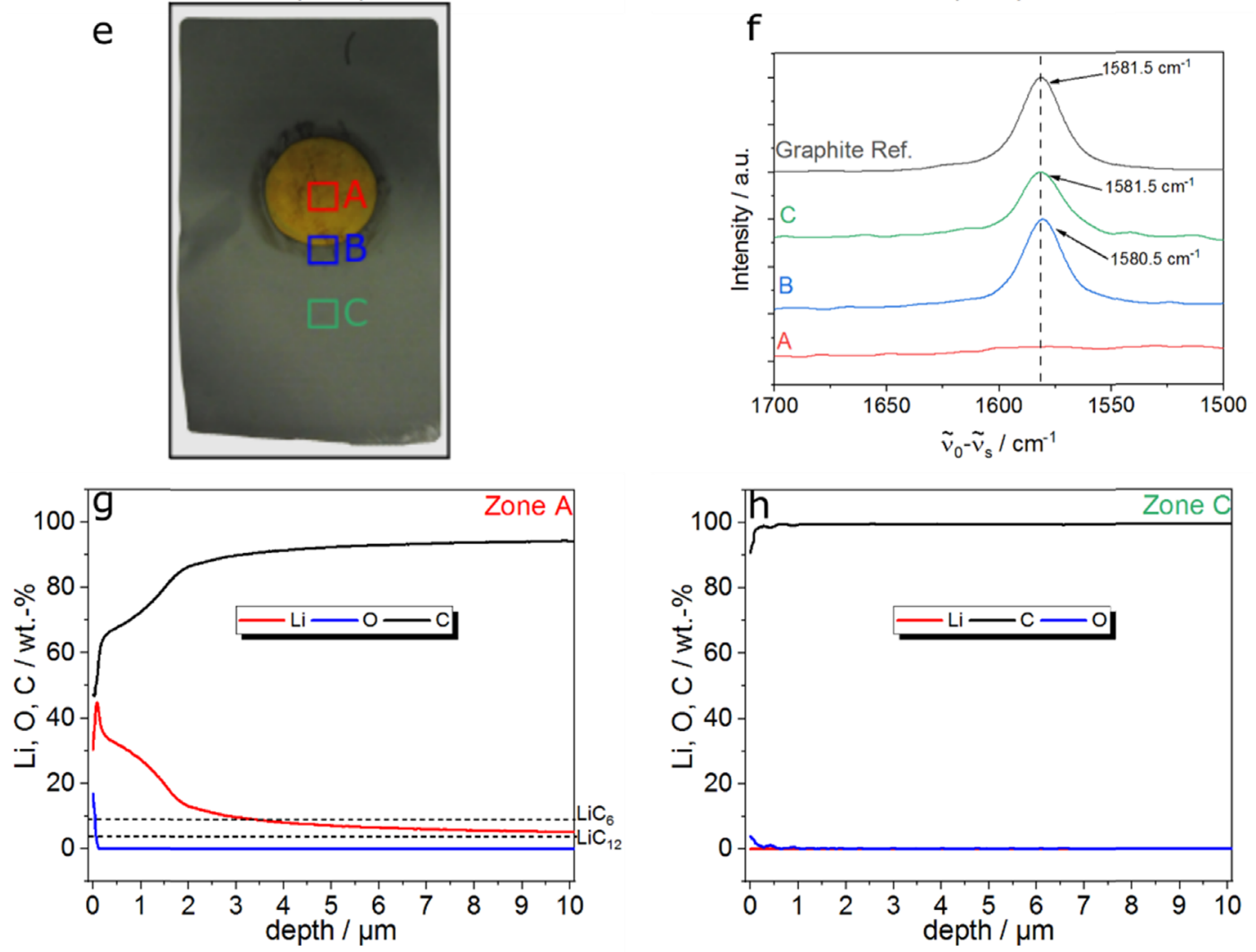

Figure 7. (a)-(d) Example for the characterization of the lithiation state of the electrodes after 4 weeks in case of the setup without electrolyte. (a) Squares $\left(0.25 \mathrm{~cm}^{2}\right)$ show in which zones Raman spectroscopy and GD-OES were conducted. (b) Raman spectra of the sample. Upper spectrum from pristine graphite electrode. (c) GD-OES depth profiling of zone A. (d) GD-OES depth profiling of zone B. (e)-(h) Electrode setup with carbonate solution without LiPF after 4 weeks at $29{ }^{\circ} \mathrm{C}$. (e) Squares $\left(0.25 \mathrm{~cm}^{2}\right)$ show in which zones Raman spectroscopy and GD-OES were conducted. (f) Raman spectra of the sample. Upper spectrum from pristine graphite electrode. (g) GD-OES depth profiling of zone A. (h) GD-OES depth profiling of zone C. 

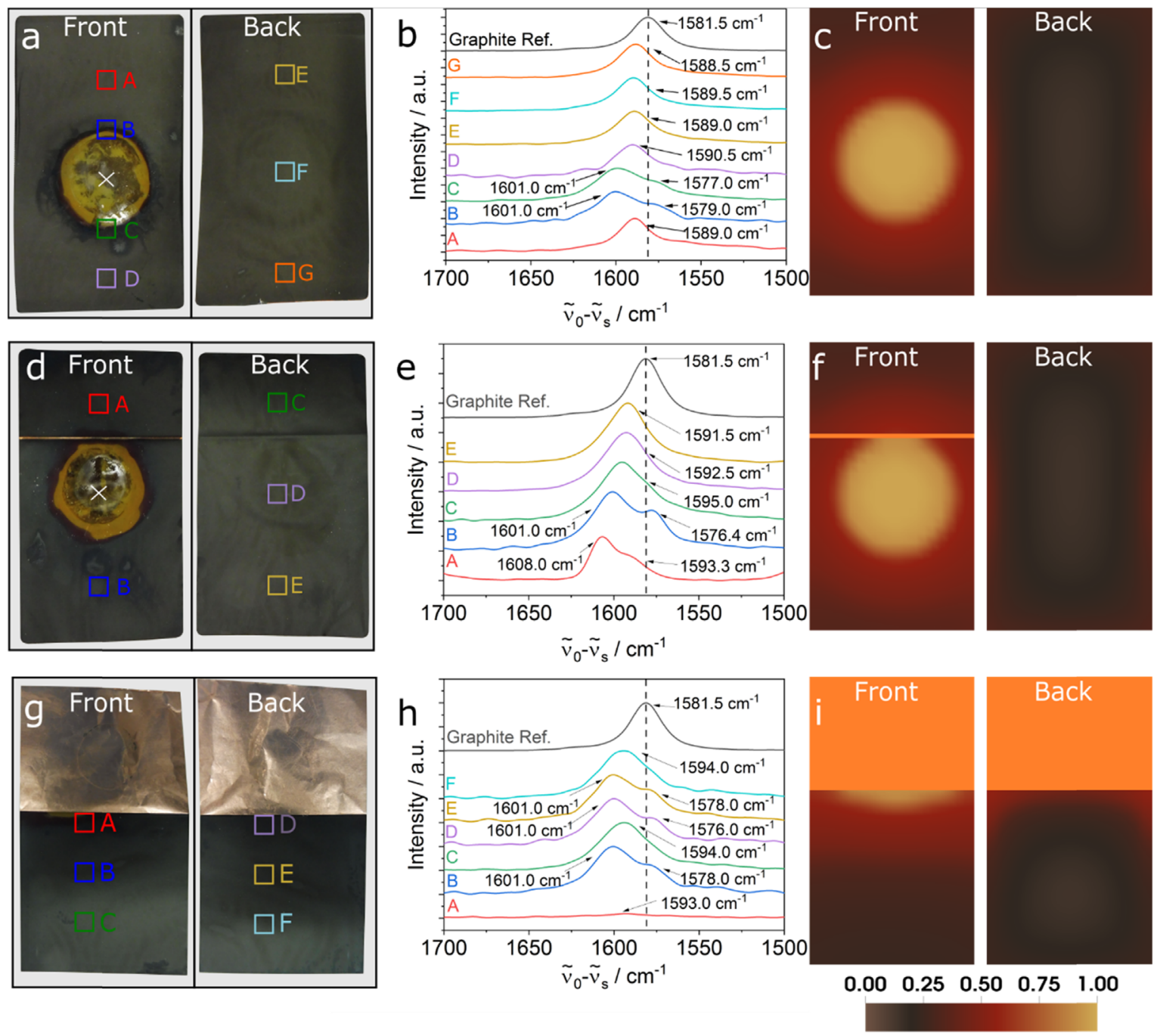

State of Charge $\mathrm{Li}_{x} \mathrm{C}_{6}$

Figure 8. Experiments with typical electrolyte solution with conductive salt. (a)-(c) Unmodified graphite electrode. (a) The squares $\left(0.25 \mathrm{~cm}^{2}\right)$ emphasize the measured positions for Raman spectroscopy in the respective color. The white X marks the former center of the Li-metal disk. (b) Raman spectra of electrode after 4 weeks at $29{ }^{\circ} \mathrm{C}$ and pristine graphite electrode as reference. (c) State of Charge distribution calculated with the simulation. (d)-(f) Electrode setup with interrupted electrode coating after 4 weeks at $29^{\circ} \mathrm{C}$. (d) Squares $\left(0.25 \mathrm{~cm}^{2}\right)$ show in which zones Raman spectroscopy was conducted. The white $\mathrm{X}$ marks the former center of the Li-metal disk. (e) Raman spectra of the sample and pristine graphite electrode as reference. (f) SOC distribution calculated with the simulation. (g)-(i) Electrode setup with Li in contact with the Cu foil after 4 weeks at $29^{\circ} \mathrm{C}$. (g) Squares $\left(0.25 \mathrm{~cm}^{2}\right)$ show in which zones Raman spectroscopy was conducted. (h) Raman spectra of the sample and pristine graphite electrode as reference. (i) SOC distribution of the simulation.

Fig. 5), while the solid diffusion pathways (2 and 3 in Fig. 5) are very slow, however happening in parallel. In addition to details of the reaction mechanism, the model studies in this work revealed interesting consequences on the following general topics:

1) The re-intercalation of electrical connected $\mathrm{Li}$ in dried out areas is possible with very slow kinetics. The lithiation degree of graphite particles near local Li deposits will increase. This will increase inhomogeneities and might have an influence on the aging behavior.

2) The results of the present paper showed that Li metal locally in electrical contact with a graphite electrode, could exhibit local SOC variations during a rest. In case of locally deposited $\mathrm{Li}$ during aging, this leads most likely to local charge inhomogenities on the negative electrode.

3) The negative electrode overhang was already reported to participate in aging mechanisms without Li deposition, depending on rest times and SOCs. ${ }^{52-55}$ From the present study it is likely that marginal $\mathrm{Li}$ deposition or homogeneous Li plating covering the whole electrode redistributes preferentially into the overhang area of the negative electrode. A lithiated overhang area most likely favors marginal Li deposition due to higher local SOCs in this region.

4) The present results suggest that in post-mortem analysis, cells with Li deposition should be disassembled as soon as possible, in order to measure the correct amount of $\mathrm{Li}$ metal. This is in accordance with results on re-intercalation of Li deposition by others. $^{12,14-17}$ In cells with higher internal pressure, e.g. cylindrical cells, it is likely that $\mathrm{Li}$ depositions re-intercalate faster due to better contact with the electrode.

5) Once electrodes are taken out of a cell in post-mortem analysis, they should be washed and dried carefully as soon as possible in order to remove electrolyte and conductive salt. Storage without external pressure and at low temperatures will slow down reintercalation of $\mathrm{Li}$.

6) Pre-lithiation by Li metal is faster in the presence of electrolyte including conductive salt. Lithiation of graphite is strongest near the $\mathrm{Li}$ metal. As suggested in former studies, ${ }^{17-20}$ a large areal 
coverage and many interfaces are preferable for direct contact pre-lithiation. We showed in our experiments that it is even possible to pre-lithiate the back of double-sided electrodes, without using two $\mathrm{Li}$ sources. It has to be investigated if the homogeneity of this pre-lithiation method is sufficient.

The present study showed important new insights into the reaction mechanism of $\mathrm{Li}$ metal with graphite electrodes, which are valuable for pre-lithiation, Post-Mortem analysis, as well as aging mechanisms such as re-intercalation of deposited Li metal. Further experiments into this direction are ongoing in our labs.

\section{Acknowledgments}

Experimental work was carried out at ZSW and simulations by the DLR at the HIU. The authors would like to thank J. Martin, M. Kasper, and M. Marinaro for helpful discussions. The authors acknowledge support by the state of Baden-Württemberg through bwHPC and the German Research Foundation (DFG) through grant no INST 40/467-1 FUGG (JUSTUS cluster). This work contributes to the research performed at CELEST (Center for Electrochemical Energy Storage Ulm-Karlsruhe).

\section{ORCID}

Simon Hein (D) https://orcid.org/0000-0002-6728-9983

Thomas Waldmann (iD https://orcid.org/0000-0003-3761-1668

\section{References}

1. S. Ahmed et al., J. Power Sources, 367, 250 (2017).

2. H. P. Lin, D. Chua, M. Salomon, H. C. Shiao, M. Hendrickson, E. Plichta, and S. Slane, Electrochem. Solid-State Lett., 4, 129 (2001).

3. J. Vetter, P. Novák, C. Veit, K.-C. Möller, J. O. Besenhard, M. Winter, M. Wohlfahrt-Mehrens, C. Vogler, and A. Hammouche, J. Power Sources, 147, 269 (2005).

4. J. C. Burns, D. A. Stevens, and J. R. Dahn, J. Electrochem. Soc., 162, A959 (2015).

5. T. Waldmann, J. B. Quinn, K. Richter, M. Kasper, A. Tost, A. Klein, and M. Wohlfahrt-Mehrens, J. Electrochem. Soc., 164, A3154 (2017).

6. D. Anseán, M. Dubarry, A. Devie, B. Y. Liaw, V. M. García, J. C. Viera, M. González, and D. Anseán, J. Power Sources, 356, 36 (2017).

7. R. V. Bugga and M. C. Smart, ECS Trans., 25, 241 (2010).

8. S. S. Zhang, K. Xu, and T. R. Jow, J. Power Sources, 160, 1349 (2006).

9. C. von Lüders, V. Zinth, S. V. Erhard, P. J. Osswald, M. Hofmann, R. Gilles, and A. Jossen, J. Power Sources, 342, 17 (2017).

10. S. Schindler, M. Bauer, M. Petzl, and M. A. Danzer, J. Power Sources, 304, 170 (2016).

11. C. Uhlmann, J. Illig, M. Ender, R. Schuster, and E. Ivers-Tiffée, J. Power Sources, 279, 428 (2015).

12. V. Zinth, C. Von Lüders, M. Hofmann, J. Hattendorff, I. Buchberger, S. Erhard, J. Rebelo-Kornmeier, A. Jossen, and R. Gilles, J. Power Sources, 271, 152 (2014).

13. Y. Reynier, R. Yazami, and B. Fultz, J. Power Sources, 119-121, 850 (2003).

14. T. Waldmann and M. Wohlfahrt-Mehrens, Electrochim. Acta, 230, 454 (2017).

15. K. Richter, T. Waldmann, N. Paul, N. Jobst, R. G. Scurtu, M. Hofmann, R. Gilles, and M. Wohlfahrt-Mehrens, ChemSusChem, 13, 529 (2020).
16. J. Wandt, P. Jakes, J. Granwehr, R. A. Eichel, and H. A. Gasteiger, Mater. Today, 21, 231 (2018)

17. H. Park, S. M. Hong, C. Jung, M. Kim, C. M. Koo, F. Xu, C. Jung, S. M. Hong, and C. M. Koo, J. Power Sources, 283, 68 (2015).

18. H. J. Kim, S. Choi, S. J. Lee, M. W. Seo, J. G. Lee, E. Deniz, Y. J. Lee, E. K. Kim, and J. W. Choi, Nano Lett., 16, 282 (2016).

19. A. Shellikeri, V. G. Watson, D. L. Adams, E. E. Kalu, J. A. Read, T. R. Jow, and J. P. Zheng, ECS Trans., 77, 293 (2017).

20. F. Holtstiege, R. Schmuch, M. Winter, G. Brunklaus, and T. Placke, J. Power Sources, 378, 522 (2018).

21. F. Holtstiege, P. Bärmann, R. Nölle, M. Winter, and T. Placke, Batteries, 4, 1 (2018).

22. J. Yan, W. J. Cao, and J. P. Zheng, J. Electrochem. Soc., 164, A2164 (2017)

23. M. Marinaro, M. Weinberger, and M. Wohlfahrt-mehrens, Electrochim. Acta, 206, 99 (2016).

24. ITWM, http://itwm.fraunhofer.de/best (2020).

25. S. Hein and A. Latz, Electrochim. Acta, 201, 354 (2016).

26. L. von Kolzenberg, A. Latz, and B. Horstmann, ChemSusChem, 13, 3901 (2020).

27. S. Das, P. M. Attia, W. C. Chueh, and M. Z. Bazant, J. Electrochem. Soc., 166 E107 (2019).

28. L. S. Kremer, A. Hoffmann, T. Danner, S. Hein, B. Prifling, D. Westhoff, C. Dreer, A. Latz, V. Schmidt, and M. Wohlfahrt-Mehrens, Energy Technol., 8, 1 (2020).

29. M. Safari and C. Delacourt, J. Electrochem. Soc., 158, A562 (2011).

30. A. Nyman, M. Behm, and G. Lindbergh, Electrochim. Acta, 53, 6356 (2008).

31. M. Fleischhammer, T. Waldmann, G. Bisle, B. I. Hogg, and M. WohlfahrtMehrens, J. Power Sources, 1181, 432 (2015).

32. J. R. Dahn, R. Fong, and M. J. Spoon, Phys. Rev. B, 42, 6424 (1990).

33. S. J. Harris, A. Timmons, D. R. Baker, and C. Monroe, Chem. Phys. Lett., 485, 265 (2010).

34. P. Maire, A. Evans, H. Kaiser, W. Scheifele, and P. Novák, J. Electrochem. Soc., 155, A862 (2008)

35. H. Honbo, K. Takei, Y. Ishii, and T. Nishida, J. Power ources, 189, 337 (2009).

36. I. Epelboin, M. Froment, M. Garreau, J. Thevenin, and D. Warin, J. Electrochem Soc., 127, 2100 (1980).

37. Z. Li, J. Huang, B. Yann Liaw, V. Metzler, and J. Zhang, J. Power Sources, 254 168 (2014).

38. N. Ghanbari, T. Waldmann, M. Kasper, P. Axmann, and M. Wohlfahrt-mehrens, J. Phys. Chem. C, 120, 22225 (2016)

39. M. Zier, F. Scheiba, S. Oswald, J. Thomas, D. Goers, T. Scherer, M. Klose, H. Ehrenberg, and J. Eckert, J. Power Sources, 266, 198 (2014).

40. T. Waldmann et al., J. Electrochem. Soc., 163, A2149 (2016).

41. P. Saha, S. Member, and S. Dey, IEEE Trans. Ind. Electron., 67, 350 (2020).

42. X. G. Yang, S. Ge, T. Liu, Y. Leng, and C. Y. Wang, J. Power Sources, 395, 251 (2018).

43. F. M. Kindermann, A. Noel, S. V. Erhard, and A. Jossen, Electrochim. Acta, 185 107 (2015).

44. L. Mandeltort and J. T. Yates, J. Phys. Chem. C, 116, 24962 (2012).

45. M. Inaba, H. Yoshida, Z. Ogumi, and S. Rod, J. Electrochem. Soc., 142 (1995).

46. C. Sole, N. E. Drewett, and L. J. Hardwick, Faraday Discuss., 172, 223 (2014).

47. Z. P. Hu and A. Ignatiev, Phys. Rev. B, 30, 4856 (1984).

48. M. T. Johnson, H. I. Starnberg, and H. P. Hughes, Surf. Sci., 178, 290 (1986).

49. P. Arora, J. Electrochem. Soc., 145, 3647 (1998).

50. Y. Wang, S. Nakamura, M. Ue, and P. B. Balbuena, J. Am. Chem. Soc., 123, 11708 (2001).

51. H. Tachikawa and S. Abe, Electrochim. Acta, 120, 57 (2014).

52. M. D. Bhatt, M. Cho, and K. Cho, Appl. Surf. Sci., 257, 1463 (2010).

53. R. Yazami and Y. F. Reynier, Electrochim. Acta, 47, 1217 (2002).

54. L. J. Hardwick, H. Buqa, and P. Novák, Solid State Ionics, 177, 2801 (2006)

55. B. Gyenes, D. A. Stevens, V. L. Chevrier, and J. R. Dahn, J. Electrochem. Soc., 162, A278 (2015). 